\title{
PENGARUH PENDIDIKAN KESEHATAN REPRODUKSI OLEH PENDIDIK SEBAYA TERHADAP PENGETAHUAN DAN SIKAP DALAM PENCEGAHAN SEKS PRANIKAH \\ DI SMAN 1 SUKAMARA KALIMANTAN TENGAH
}

\author{
${ }^{1}$ Jenny Oktarina \\ ${ }^{1}$ STIKes Borneo Cendekia Medika Pangkalan Bun \\ ${ }^{1}$ Email: oktarina.jenny@yahoo.co.id
}

\begin{abstract}
ABSTRAK
Pendahuluan: Remaja merupakan masa transisi dari anak-anak menjadi dewasa. Usia remaja berada pada rentang 10-19 tahun. Seiring dengan masa transisi, remaja mempunyai permasalahan yang kompleks. Salah satunya adalah perilaku seks pra nikah. faktor yang mempengaruhi seks pra nikah pada remaja adalah kurangnya informasi dan pengetahuan mengenai kesehatan reproduksi. Pendidikan kesehatan reproduksi merupakan salah satu cara untuk mengurangi dampak negatif dan mencegah seks pra nikah. Tujuan: Penelitian ini bertujuan untuk mengetahui pengaruh pendidikan kesehatan reproduksi pada pengetahuan dan sikap remaja dalam pencegahan hubungan seks pra nikah di SMAN 1 Sukamara, Provinsi Kalimantan Tengah. Metode: Penelitian ini menggunakan rancang bangun quasi experimental (eksperimental semu) jenis pre test - post test control group design. Pengambilan sampel dilakukan dengan menggunakan teknik simple random sampling. Kuesioner digunakan untuk pengumpulan data dan analisis dilakukan dengan menggunakan uji t sampel berpasangan. Pendidikan kesehatan reproduksi diberikan tiga kali. Pre test dan post test dilakukan untuk mengukur pengetahuan dan sikap. Hasil: terdapat perbedaan yang bermakna pada kelompok kontrol dan kelompok perlakuan pada pengetahuan dan sikap remaja. pengetahuan pada remaja $\mathrm{p}=0,000(\mathrm{p}<0,05)$ dan sikap pada remaja $\mathrm{p}=0,014(\mathrm{p}<0,05)$. Kesimpulan: Ada pengaruh pendidikan kesehatan reproduksi terhadap peningkatan pengetahuan dan sikap remaja di SMAN 1 Sukamara, Provinsi Kalimantan Tengah.
\end{abstract}

Kata kunci: Pendidikan Kesehatan Reproduksi, Pengetahuan, Sikap, Seks Pra Nikah.

\section{THE INFLUENCE OF REPRODUCTIVE HEALTH EDUCATION BY PEOPLE EDUCATION ON KNOWLEDGE AND ATTITUDE IN PRE-PRIVATE SEX PREVENTIONIN SMAN 1 SUKAMARA KALIMANTAN CENTRAL}

\section{ABSTRACT}

Background: Teenage is a transition period from children to adults. Teenagers are in the range of 10-19 years. Along with the transition period, adolescents have complex problems. One of them is premarital sexual behavior. factors affecting premarital sex in adolescents are lack of information and knowledge about reproductive health. Reproductive health education is one way to reduce the negative effects and prevent premarital sex. Objective: This study aims to determine the effect of reproductive health education on the knowledge and attitudes of adolescents in the prevention of premarital sex at SMAN 1 Sukamara, Central Kalimantan Province. Method: This study used a quasi experimental (quasi-experimental) design type of pre-test - post test control group 
design. Sampling is done using simple random sampling technique. The questionnaire was used for data collection and analysis was performed using paired sample t-tests. Reproductive health education is given three times. Pre test and post test are conducted to measure knowledge and attitudes. Results: There were significant differences in the control group and the treatment group for adolescent knowledge and attitudes. knowledge in adolescents $p=0,000(p<0.05)$ and attitudes in adolescents $p=0.014$ ( $p$ $<0.05)$. Conclusion: There is an effect of reproductive health education on improving the knowledge and attitudes of adolescents at SMAN 1 Sukamara, Central Kalimantan Province.

Keywords: Reproductive Health Education, Knowledge, Attitude, Premarital Sex

\section{PENDAHULUAN}

Kehidupan remaja merupakan kehidupan yang sangat menentukan bagi kehidupan masa depan mereka selanjutnya. Pada tahun 2010 jumlah remaja usia 10-19 tahun di Indonesia sebesar 43.548.576 jiwa atau $18,33 \%$ dari total jumlah penduduk Indonesia yang mencapai 237.641.326 jiwa. Hal ini berarti bahwa seperlima penduduk indonesia adalah remaja berusia 10-19 tahun (Badan Pusat Statistik, 2010).

Melihat jumlahnya yang sangat besar, remaja juga mempunyai permasalahan yang kompleks seiring dengan masa transisi yang dialami remaja. Masalah yang perlu mendapatkan perhatian khusus seperti masalah perilaku seks pranikah, NAPZA (Narkotika, Psikotropika dan Zat Adiktif) dan HIV/AIDS (Wahyuni dan Rahmadewi, 2011).

Perilaku seksual pranikah di kalangan remaja diperkuat dengan data dari Depkes Tahun 2009 di 4 kota besar (Medan, Jakarta Pusat, Bandung dan Surabaya), menunjukkan bahwa 35,9\% remaja mempunyai teman yang sudah pernah melakukan hubungan seks pranikah dan 6,9\% responden telah melakukan hubungan seks pranikah (Depkes RI, 2009). World Health Organization (WHO) memperlihatkan bahwa semakin meningkat pula aktivitas seksual di antara kaum muda di kawasan Asia-Pasifik. Hasil RISKESDAS tahun 2010 diketahui bahwa Indonesia termasuk negara dengan persentase pernikahan usia muda tinggi di dunia (ranking 37) (Kementerian Kesehatan, 2009).

Perilaku seksual remaja memiliki kecenderungan sikap yang permisif pada remaja terhadap perilaku seks bebas atau perilaku seks di luar nikah. Sikap permisif remaja terhadap perilaku seks bebas didukung oleh terbatasnya pengetahuan remaja tentang kesehatan reproduksi remaja (Luthfie R.E, 2008). Survei Dasar Kesehatan Reproduksi Republik Indonesia (SDKRI) di Kota Manado tahun 2000 menunjukkan pengetahuan dasar yang dimiliki responden mengenai kesehatan reproduksi relatif terbatas. Keadaan ini dapat diketahui dari $57,78 \%$ responden tidak mengetahui pengertian seksualitas. Pengetahuan remaja tentang kesehatan reproduksi sangat rendah yaitu sekitar $75 \%$. Rendahnya pengetahuan remaja tersebut berdampak pada perilaku seksual remaja menuju ke arah yang sangat membahayakan atau ke perilaku seksual yang berisiko (Aryani, 2010).

Menanggapi permasalahan tersebut Pusat Informasi dan Konseling Remaja (PIKR) (Badan Kependudukan Keluarga Berencana Nasional, 2008). BKKBN mengembangkan program kelompok umur sebaya. Berdasarkan hasil laporan dari BKKBN jumlah PIK-R yang telah terbentuk di Indonesia, adalah sebanyak 2.773 PIK-R yang didirikan di sekolah- sekolah sebanyak $55 \%$, di Lembaga Swadaya Masayarakat (LSM) $15 \%$ dan 35\% yang didirikan di Karang Taruna (Siswanto, 2008). Keberadaan dan peranan Pendidik Sebaya di lingkungan remaja sangat penting artinya sebagai narasumber kesehatan reproduksi remaja (KRR) bagi teman sebayanya. Keterampilan yang didapatkan melalui pelatihan dapat untuk meningkatkan ketrampilan dalam berkomunikasi dan meningkatkankan kepercayaan kepada teman sebayanya yang membutuhkan pemenuhan keingintahuan mengenai KRR.

Menurut data SMAN 1 Sukamara jumlah siswi yang dikeluarkan dari sekolah 
akibat hamil diluar nikah adalah sebagai berikut pada tahun 2013 jumlah siswi yang dikeluarkan adalah 2 siswi, pada tahun 2014 tidak ada siswi yang dikeluarkan karena hamil diluar nikah, pada tahun 2015 jumlah siswi yang dikeluarkan adalah 1 siswi. Pada tahun 2016 jumlah siswi yang dikeluarkan adalah 3 siswi. Dari data tersebut jumlah siswi yang dikeluarkan mengalami peningkatan dari tahun 2015 ke tahun 2016.

Dengan adanya peranan dari pusat informasi konseling remaja di berbagai setiap wilayah diharapkan mampu memberikan dan mensosialisasikan permasalahan berkaitan seputar Seksualitas, HIV, AIDS dan NAPZA sehingga menekan jumlah besarnya permasalahan yang dihadapi remaja setiap tahunnya

\section{METODE}

Ditinjau dari tujuan dan sifatnya, rancang bangun penelitian ini adalah quasi experimental (eksperimental semu) jenis pre test - post test control group design.

Tempat penelitian dilakukan di SMAN 1 Sukamara Kalimantan Tengah. Waktu penelitian ini pada bulan Agustus 2017. Populasi dalam penelitian ini adalah seluruh siswa kelas 1 SMAN 1 Sukamara yang berjumlah 242 siswa. Sampel yang diambil adalah siswa kelas 1 yang memenuhi kriteria inklusi. Kriteria inklusi dalam penelitian ini adalah remaja laki-laki maupun perempuan kelas 1 yang bersekolah di SMAN 1 Sukamara dan bersedia menjadi responden. Sedangkan kriteria eksklusi adalah Remaja yang pernah mendapatkan pendidikan kesehatan reproduksi oleh pendidik sebaya. Teknik sampling yang digunakan adalah simple random sampling.

Variabel independen dalam penelitian ini adalah pemberian pendidikan kesehatan reproduksi oleh pendidik sebaya dan variabel dependen dalam penelitian ini adalah pengetahuan dan sikap.

Sumber data dalam penelitian ini berupa data primer yang diperoleh langsung dari responden berupa pengetahuan dan sikap remaja tentang kesehatan reproduksi dan data sekunder yang diperoleh dari sekolah. Analisa data dalam penelitian ini dengan menggunakan uji statistik yaitu Uji t sampel berpasangan dan Uji t dua sampel bebas.

\section{HASIL}

Variabel independen dalam penelitian ini yaitu pemberian pendidikan kesehatan reproduksi oleh pendidik sebaya dan variabel dependen dalam penelitian ini yaitu pengetahuan dan sikap. Dengan jumlah responden 25 orang kelompok perlakuan dan 25 orang kelompok kontrol.

1. Pengetahuan siswa

Pengetahuan remaja tentang kesehatan reproduksi dapat diamati dengan memberikan pre test dan post test pada kelompok kontrol dan kelompok perlakuan yang dapat dilihat pada tabel sebagai berikut:

Tabel $1.1 \quad$ Distribusi frekuensi pengetahuan pada kelompok perlakuan tentang kesehatan reproduksi pada siswa kelas X di SMAN 1 Sukamara Tahun 2016

\begin{tabular}{ccccc} 
& \multicolumn{5}{c}{ Kelompok Perlakuan } \\
\cline { 2 - 5 } Kategori & \multicolumn{3}{c}{ Pre } & \multicolumn{3}{c}{ Post } \\
\cline { 2 - 5 } Pengetahuan & Jumla & $\%$ & Jumla & $\%$ \\
& $\mathrm{~h}$ & \multicolumn{3}{c}{$\mathrm{h}$} \\
\hline Baik & 3 & 12 & 20 & 80 \\
Cukup & 7 & 28 & 5 & 20 \\
Kurang & 15 & 60 & 0 & 0 \\
\hline Total & 25 & 100 & 25 & 100 \\
\hline
\end{tabular}

\begin{abstract}
Pengetahuan kelompok perlakuan sebelum diberi pendidikan kesehatan reproduksi mayoritas masuk kedalam kategori kurang sebanyak 15 orang $(60 \%)$, sedangkan setelah diberikan pendidikan kesehatan reproduksi sebagian besar masuk kedalam kategori baik sebanyak 20 orang (80\%).
\end{abstract}

Tabel 1.2 Distribusi frekuensi pengetahuan pada kelompok kontrol tentang kesehatan reproduksi pada siswa kelas X di SMAN 1 Sukamara Tahun 2016.

\begin{tabular}{ccccc}
\multirow{2}{*}{ Kategori } & \multicolumn{3}{c}{ Kelompok Kontrol } \\
\cline { 2 - 5 } Pengetahua & \multicolumn{2}{c}{ Pre } & \multicolumn{3}{c}{ Post } \\
\cline { 2 - 5 } n & Jumla & $\%$ & Jumla & $\%$ \\
& $\mathrm{~h}$ & & $\mathrm{~h}$ & \\
\hline Baik & 1 & 4 & 1 & 4 \\
Cukup & 10 & 40 & 10 & 40 \\
Kurang & 14 & 56 & 14 & 56 \\
\hline Total & 25 & 100 & 25 & 100 \\
\hline
\end{tabular}


Pengetahuan kelompok kontrol pada saat pre dan posttest tidak mengalami perubahan.

Tabel 1.3 Perubahan skor pengetahuan tentang kesehatan reproduksi pre dan post pada siswa kelas $\mathrm{X}$ di SMAN 1 Sukamara

\begin{tabular}{cccc}
\hline \multirow{2}{*}{$\begin{array}{c}\text { Kelompo } \\
\mathrm{k}\end{array}$} & \multicolumn{2}{c}{ Pengetahuan } & $\mathrm{p}$ \\
\cline { 2 - 3 } & \multicolumn{2}{c}{ Rerata (SD) } & \\
\cline { 2 - 3 } & Pre & Post & \\
\hline \multirow{2}{*}{ Perlakuan } & 61,0 & $78,2,(4,4)$ & $0,000^{*}(\mathrm{~s})$ \\
Kontrol & 61,3 & 63,3 & $0,520^{*}$ \\
& $(12,7)$ & $(11,1)$ & (ts) \\
\hline
\end{tabular}

$*=\mathrm{Uji} \mathrm{t}$

sampel berpasangan

$\mathrm{s}=$ Signifikan

ts $=$ Tidak signifikan

Rata-rata pengetahuan siswa pada kedua kelompok saat pre test masuk dalam kategori cukup, setelah diberi pendidikan kesehatan reproduksi pada kelompok perlakuan ratarata berpengetahuan baik, sedangkan pada elompok kontrol rata-rata berpengetahuan

Analisis statistik uji t dua sampel bebas pada rerata pre test menunjukan nilai $\mathrm{p}=0,926$ $(p>0,05)$ tidak terdapat perbedaan bermakna pengetahuan kelompok perlakuan dan kontrol. Berbeda dengan uji beda pengetahuan antara kedua kelompok pada rerata nilai post test menunjukkan ada perbedaan yang bermakna dengan nilai sig $\mathrm{p}=0,000 \quad(\mathrm{p}<0,05)$ berarti bahwa pada saat setelah diberi pendidikan kesehatan reproduksi, terdapat perbedaan pengetahuan antara kelompok perlakuan dan kelompok kontrol.

1. Sikap siswa

Tabel 2.1 Sikap remaja pada kelompok perlakuan terhadap perilaku hubungan seks pranikah di SMAN 1 Sukamara tahun 2016 cukup. Dari analisis statistik dengan menggunakan uji $\mathrm{t}$ sampel berpasangan $(\alpha=0,05)$ pada kelompok perlakuan didapatkan nilai $\mathrm{p}=0,000 \quad(\mathrm{p}<0,05)$ menunjukkan adanya perbedaan bermakna antara rerata pre test dan post test, sedangkan pada kelompok kontrol didapatkan hasil $\mathrm{p}=0,520 \quad(\mathrm{p}>0,05)$ yang berarti tidak ada perbedaan rerata pre test dan post test, sehingga dapat disimpulkan bahwa pemberian pendidikan kesehatan reproduksi dapat meningkatkan pengetahuan tentang kesehatan reproduksi pada remaja

Tabel 1.4 Perbedaan skor pengetahuan antara kelompok perlakuan dan kelompok control

\begin{tabular}{cllll}
\hline \multirow{2}{*}{ Kategori } & \multicolumn{3}{c}{ Kelompok Perlakuan } \\
\cline { 2 - 5 } Sikap & \multicolumn{2}{c}{ Prel } & \multicolumn{2}{c}{ Post } \\
\cline { 2 - 5 } & $\begin{array}{l}\text { Jumla } \\
\text { h }\end{array}$ & $\%$ & Jumlah & $\%$ \\
\hline
\end{tabular}

$*=$ Uji $\mathrm{t}$ dua sampel bebas

$\mathrm{s}=$ Signifikan

$\mathrm{ts}=$ Tidak signifikan

\begin{tabular}{ccc}
\multirow{2}{*}{ Kelompok } & \multicolumn{2}{c}{ Pengetahuan } \\
\cline { 2 - 3 } & \multicolumn{2}{c}{ Rerata (SD) } \\
\cline { 2 - 3 } & Pre & Post \\
\hline Perlakuan & $61,0(11,6)$ & $78,2,(4,4)$ \\
Kontrol & $61,3(12,7)$ & 63,3 \\
& & $(11,1)$ \\
\hline P & $0,926^{*}(\mathrm{ts})$ & $0,000^{*}(\mathrm{~s})$ \\
\hline
\end{tabular}

Terdapat sikap negatif pada kelompok perlakuan sebelum diberi pendidikan kesehatan reproduksi sebanyak 5 responden (20\%), kemudian setelah diberi pendidikan seksual sebagian besar sikap masuk dalam kategori positif yaitu sebanyak 25 responden $(100 \%)$.

Tabel 2.2 Sikap remaja pada kelompok kontrol terhadap perilaku hubungan seks pranikah di SMAN 1 Sukamara tahun 2016 


\begin{tabular}{ccc}
\hline \multirow{2}{*}{ Kelompok } & \multicolumn{2}{c}{ Sikap } \\
\cline { 2 - 3 } & \multicolumn{2}{c}{ Rerata (SD) } \\
\cline { 2 - 3 } Perlakuan & $67,6(10,1)$ & $75(6,5)$ \\
Kontrol & $66(6,5)$ & $69,2(9,3)$ \\
\hline $\mathrm{p}$ & $0,486^{*}(\mathrm{ts})$ & $0,014^{*}(\mathrm{~s})$ \\
\hline
\end{tabular}

$*$ = Uji t dua sampel bebas

$\mathrm{s}=$ Signifikan

ts $=$ Tidak signifikan

Menyebutkan pada kelompok kontrol sikap pada pre test terdapat 5 responden (20\%) yang bersikap negatif dan pada post test ada 19 responden (76\%) yang bersikap positif.

Tabel 2.3 Perubahan skor sikap remaja terhadap perilaku hubungan seks pranikah pre test dan post test pada siswa kelas $\mathrm{X}$ di SMAN 1 Sukamara tahun 2016

Analisis statistik terdapat 2 sampel bebas pada pre test menunjukkan nilai $p=0,486 \quad(p>0,05)$ berarti tidak terdapat perbedaan bermakna sikap kelompok perlakuan dan kontrol. Hal ini berarti bahwa pada saat sebelum diberi pendidikan seksual, kedua kelompok berada pada tingkat sikap yang sama. Setelah diberikan pendidikan kesehatan reproduksi didapatkan perbedaan yang bermakna dengan nilai $\mathrm{p}=0,014$ $(p<0,05)$ yang berarti terdapat perbedaan sikap antara kelompok perlakuan dan kelompok kontrol. Dapat disimpulkan bahwa pendidikan seksual berpengaruh terhadap peningkatan sikap remaja terhadap perilaku hubungan seks pranikah.

\section{PEMBAHASAN}

\section{Pengetahuan Remaja tentang Kesehatan Reproduksi di SMAN 1 Sukamara}

Berdasarkan hasil penelitian ini ratarata pengetahuan pada kedua kelompok masuk dalam kategori rendah, hal ini berarti bahwa kelompok perlakuan dan kelompok kontrol mempunyai pengetahuan yang homogen pada keadaan awal. Tingkat pengetahuan yang rendah ini dikarenakan

\begin{tabular}{cccc}
\hline \multirow{2}{*}{$\begin{array}{c}\text { Kelompo } \\
\text { k }\end{array}$} & \multicolumn{2}{c}{ Sikap } & \multirow{2}{*}{ Rerata (SD) } \\
\cline { 2 - 3 } & Pre & Post & \\
\hline Perlakuan & $67,6(10,1)$ & $75(6,5)$ & $0,004^{*}(\mathrm{~s})$ \\
Kontrol & $66(6,5)$ & $69,2(9,3$ & $0,184^{*}$ \\
& ) & (ts) \\
\hline
\end{tabular}

* = Uji t sampel berpasangan

$\mathrm{s}=$ Signifikan

ts $=$ Tidak signifikan

Rerata sikap pada pre test kedua kelompok masuk dalam kategori positif dan terdapat perbedaan bermakna antara rerata pre test dan post test pada kelompok perlakuan, hal ini dibuktikan dengan hasil uji statistik nilai $\mathrm{p}=0,004 \quad(\mathrm{p}<0,05)$, sedangkan pada kelompok kontrol didapatkan hasil sig $\mathrm{p}=0,184 \quad(\mathrm{p}>0,05)$ yang berarti tidak ada perbedaan rerata pre test dan post test. Perubahan sikap juga ditunjukkan dengan nilai $\mathrm{p}=0,004$, sehingga dapat disimpulkan pendidikan kesehatan reproduksi dapat meningkatkan sikap remaja.

kurang meratanya informasi mengenai kesehatan reproduksi khusus untuk remaja. Berdasarkan wawancara dari guru Bimbingan Konseling di SMAN 1 Sukamara informasi khusus mengenai kesehatan reproduksi oleh pendidik sebaya melalui Pusat Informasi dan Konseling Remaja pernah diberikan tetapi hanya sebatas kepada anggotanya saja dan untuk diluar anggota tidak pernah diberikan, padahal seharusnya informasi tersebut harus diberikan kepada semua siswa. Sedangkan, disekolah hanya diajarkan pengetahuan dasar reproduksi dasar manusia yang masuk dalam pelajaran biologi.

Rerata nilai pengetahuan setelah diberikan pendidikan kesehatan reproduksi menjadi baik. Peningkatan pengetahuan yang didapatkan melalui pendidikan kesehatan reproduksi akan memberikan tambahan informasi tentang perubahan alat reproduksi pada laki-laki dan perempuan, kesehatan reproduksi remaja, dampak dari kehamilan remaja termasuk penyakit menular seksual. Hal ini didukung oleh Imron (2012) mengungkapkan bahwa pendidikan kesehatan reproduksi bagi remaja dimaksudkan untuk dapat memberikan pengenalan dan pencegahan bagi remaja dalam mensosialisasikan pengetahuan, sikap, dan perilaku reproduksi yang sehat sebagai dasar 
bagi pengembangan pembinaan, komunikasi, informasi, dan edukasi bagi remaja

Hasil tersebut juga didukung oleh Notoatmodjo (2010) yaitu pengetahuan merupakan hasil tahu dari penginderaan terhadap suatu objek tertentu kemudian akan mempersepsikan hal tersebut sesuai dengan pengetahuan yang dimiliki, sehingga setelah diberikan informasi mengenai pendidikan kesehatan reproduksi perubahan akan terjadi dari yang tadinya berpengetahuan rendah atau sedang menjadi tinggi dan akan berperilaku yang lebih baik lagi.

Hasil penelitian ini sesuai dengan penelitian Sriasih (2013) pendidikan seksualitas remaja oleh pendidik sebaya berpengaruh secara signifikan terhadap pengetahuan dan sikap remaja. Pengetahuan merupakan hal yang sangat penting dalam proses terbentuknya tindakan seseorang. Seseorang harus tahu terlebih dahulu arti dan manfaat perilaku bagi dirinya, kemudian seseorang akan mengadopsi perilaku baru. Perilaku yang didasari oleh pengetahuan akan lebih awet daripada perilaku yang tidak didasari oleh pengetahuan (Notoatmodjo, 2007).

Kusumastuti (2010) mengemukakan bahwa pendidikan kesehatan reproduksi remaja yang diberikan oleh pendidik sebaya akan dapat memberikan pengetahuan yang diharapkan dapat merubah sikap. Menurut Amrillah (2006), semakin tinggi pengetahuan kesehatan reproduksi yang dimiliki remaja maka semakin rendah perilaku seksual pranikahnya, begitu juga sebaliknya.

Pada kelompok kontrol tidak terdapat perbedaan pengetahuan antara pre test dan post test, hal ini dikarenakan pada kelompok kontrol tidak diberikan pendidikan kesehatan reproduksi, mereka hanya mendapatkan informasi kesehatan reproduksi melalui leaflet, sehingga tidak maksimal. Pada kelompok kontrol terjadi peningkatan walaupun tidak sebanyak kelompok perlakuan, meningkatnya pengetahuan pada kelompok kontrol bisa disebabkan karena setelah mengerjakan pre test, remaja diberi leaflet tentang kesehatan reproduksi.

\section{Sikap Remaja Terhadap Perilaku Hubungan Seks Pranikah di SMAN 1 Sukamara}

Pada kedua kelompok menunjukkan hasil rata-rata pre test responden mempunyai sikap positif, hal ini membuktikan bahwa tidak selamanya sikap didapat dari pendidikan, sikap dapat terbentuk dari pengaruh lingkungan sekitar yaitu teman, orang tua, atau media massa (Azwar, 2011).

Pada pengukuran nilai sikap kelompok perlakuan terdapat peningkatan sebelum dan sesudah diberi pendidikan kesehatan reproduksi dari sikap negatif menjadi positif. Hasil nilai sikap ini ditunjang oleh nilai pengetahuan responden. Pernyataan ini didukung oleh pendapat Sarwono (2011) sikap dibentuk melalui proses belajar sosial yaitu proses dimana individu memperoleh informasi dari orang lain.

Penelitian lain yang mendukung hasil penelitian ini adalah penelitian Asih Dwi Arosna (2014) mengatakan ada pengaruh sikap mahasiswa di FIK-UMS yang sebelum dan sesudah mengikuti pendidikan kesehatan reproduksi. Menurut penelitian Lestary dan Sugiharty tahun 2011, salah satu faktor yang secara signifikan berhubungan dengan perilaku berisiko pada remaja diantaranya adalah sikap. Sikap dapat menimbulkan cara berpikir tertentu dalam masyarakat dan cara berpikir ini mempengaruhi tindakan untuk membuat keputusan. Penelitian ini menunjukkan bahwa beberapa responden yang sebelumnya mempunyai sikap negatif berubah menjadi sikap yang positif setelah diberikan pendidikan seksual (Maulana, 2009). Hal ini sesuai dengan teori Mubarak dalam Fitriani (2011), yaitu dalam merubah sikap dapat dilakukan dengan pembinaan melalui pendidikan kesehatan. Hal tersebut disebutkan dapat meningkatkan pengetahuan sehingga dapat merespon sikap mengarah kepada perilaku yang lebih baik.

Sikap negatif yang ditunjukkan dalam penelitian ini adalah sikap dimana remaja itu setuju dan menganggap perilaku seks pranikah merupakan perilaku bagian dari cinta serta sikap yang tidak memikirkan dampak buruk dari perilaku seks pranikah, sehingga ditakutkan sikap yang negatif dapat berisiko berperilaku seks pranikah karena menurut penelitian Hakim (2012) bahwa ada hubungan antara sikap dengan kejadian perilaku seks berisiko pada remaja.

\section{KESIMPULAN DAN SARAN Kesimpulan}


Pemberian pendidikan kesehatan reproduksi oleh pendidik sebaya dapat meningkatkan pengetahuan dan sikap siswa dalam pencegahan seks pra nikah di SMAN 1 Sukamara.

\section{Saran}

Pihak sekolah agar dapat memotivasi kegiatan PIK-R (pusat informasi dan konseling remaja) khususnya anggotanya baik yang jadi pendidik sebaya maupun yang jadi konselor sebaya agar lebih aktif dalam menjalankan tugas dan fungsinya.

Bagi guru BK di SMAN 1 Sukamara agar dapat meningkatkan perannya sebagai konselor dan memonitoring siswa yang terkait seksualitas remaja. Program kesehatan reproduksi remaja dapat digabungkan pada program UKS, terutama untuk mempersertakan siswa kelas I SMA.

Pendidikan kesehatan reproduksi untuk remaja dapat dilanjutkan dan dilakukan secara berkala misalnya 1 bulan sekali dengan sasaran siswa yang bukan anggota PIK-R.

\section{DAFTAR PUSTAKA}

Amrillah. 2006. Hubungan antara Pengetahuan Seksualitas dan Kualitas Kominikasi Anak Orang Tua dengan Perilaku Seksual Pranikah. Skripsi Ilmiah. Surakarta: Fakultas Psikologi Universitas Muhammadiyah Surakarta.

Arosna, Asih dwi. 2014. Pengaruh pendidikan kesehatan reproduksi terhadap pengetahuan dan sikap mahasiswa di FIK-UMS. Skripsi. Surakarta: Fakultas Ilmu Kesehatan Universitas Muhammadiyah Surakarta.

Aryani. 2010. Kesehatan Remaja Problem dan Solusinya. Jakarta: Salemba Medika.

Azwar, S. 2011. Sikap dan Perilaku. Dalam: Sikap Manusia Teori dan Pengukurannya. 2nd edn. Yogyakarta: Pustaka Pelajar.

Badan Kependudukan Keluarga Berencana Nasional. 2008. Kurikulum dan Modul Pelatihan Pengelolaan Pusat Informasi dan Konseling Kesehatan Reproduksi Remaja. Jakarta: BKKBN.
Badan Pusat Statistik. 2010. Data Statistik Indonesia: Jumlah Penduduk menurut Kelompok Umur, Jenis Kelamin, Provinsi, dan Kabupaten/Kota, 2005. Tersedia pada:http://demografi.bps.go.id/versi 1/index.php?option=com_tabel\&task $=\&$ Ite $\operatorname{mid}=1 \quad[$ diakses 2 agustus 2016]

Depkes RI. 2009. Sistem Kesehatan Nasional. Jakarta.

Fitriani. 2011. Hubungan Pendidikan Seks Dengan Perilaku Seksual Pada Remaja di SMK Prayatna-1 Medan. Skripsi. tersedia pada: http://repository.usu.ac.id/handle/123 456789/24068 [diakses 7 Agustus 2016].

Hakim, D.M. 2012. Faktor-faktor yang Berhubungan dengan Kejadian Perilaku Seks Berisiko pada Remaja Tunarungu di Sekolah Menengah Atas Luar Biasa (SMALB) Kota Padang Tahun 2010. Skripsi. Padang: Fakultas Kesehatan Masyarakat Universitas Andalas.

Imron, Ali. 2012. Pendidikan kesehatan reproduksi remaja: peer educator dan efektivitas program PIK-KRR di sekolah. Jogjakarta: Ar-Ruzz Media.

Kementerian Kesehatan. 2009. Laporan Hasil Riset Kesehatan Dasar, RISKESDAS Indonesia Tahun 2010. Jakarta : Balitbangkes.

Kusumastuti, fadhila. 2010. Hubungan antara pengetahuan dengan sikap seksual pra nikah remaja. Karya tulis ilmiah surakarta. Universitas Sebelas Maret.

Luthfie R.E. 2008. Seksualitas Remaja. Tersedia pada http.//www.bkkbn.go.id [diakses pada 4 mei 2016]

Maulana H.D.J. 2009. Promosi Kesehatan. Jakarta: EGC.

Notoatmodjo, S. 2010. Ilmu Perilaku Kesehatan. Jakarta: Rineka Cipta.

Notoatmodjo, S. 2007. Promosi Kesehatan dan Ilmu Perilaku. Jakarta: Rineka Cipta.

Sarwono. S.W. 2011. Psikologi Remaja. Jakarta: PT Raja Grafindo Persada.

Siswanto. 2008. Berbagai faktor yang Mempengaruhi Perilaku Seksual Remaja di Jawa Tengah: Implikasinya terhadap Kebijakan dan 
Layanan Kesehatan Seksual dan Reproduksi. Makara Kesehatan. Vol. 10 No 1 Juni 2008. Hal. 29-40.

Sriasih, K.N.G.. 2013. Pengaruh Pendidikan Seksualitas Remaja oleh Pendidik Sebaya terhadap Pengetahuan dan Sikap Remaja tentang Bahaya Seks Bebas. Jurnal Skala Husada. Vol. 10 No. 1 April 2013. Hal. 13-19. Poltekkes Denpasar. Tersedia pada : http://www.poltekkes-denpasar.ac.id. [diakses 1 Mei 2016]

Wahyuni, D. dan Rahmadewi. 2011. KAJIAN PROFIL PENDUDUK REMAJA (1024 THN): Ada apa dengan Remaja?. Pusdu BKKBN, Seri I (No.6). 